\title{
Bem-estar em invertebrados: um parâmetro ético de responsabilidade científica e social da pesquisa?
}

\author{
¿Bienestar en invertebrados: un parámetro \\ ético de la responsabilidad científica y social \\ de la investigación?
}

\section{Invertebrate well-being: an ethical parameter of scientific and social research responsibility?}

Fecha de recepción: 9 de mayo de 2017

Fecha de evaluación: 25 de julio de 2017

Fecha de aceptación: 21 de noviembre de 2017

Publicación en línea: 1 de octubre de 2017

Marta Luciane Fischer*

Juliana Zacarkin Santos***

\begin{abstract}
Cómo citar:
Fischer, M. L. y Zacarkin Santos, J. (2018). Bemestar em invertebrados: um parâmetro ético de responsabilidade científica e social da pesquisa? Revista Latinoamericana de Bioética, 18(1), 18-35. Doi: https://doi.org/10.18359/rlbi.2865
\end{abstract}

* Bióloga, Mestre e Doutora em Zoologia. Programa de Pós-Graduação em Bioética. Docente da Escola Ciências da Vida. Pontifícia Universidade Católica do Paraná (PUCPR). Curitiba, Paraná, Brasil. E-mail: marta.fischer@ pucpr.br. ORCID: http://orcid.org/0000-0002-1885-0535

** Licenciada em Ciências Biológicas e Mestre pelo Programa de Pós-graduação em Bioética da PUCPR. E-mail: juliana.zacarkin@gmail.com. ORCID: https://orcid.org/0000-0002-8577-6603 
Objetivou-se avaliar a promoção do bem-estar de invertebrados usados em pesquisa por meio da sua representação no meio científico, divulgação das pesquisas e inclusão nos debates éticos. A análise atestou predomínio de abordagens biológicas, utilitaristas em animais de interesse médico e econômico, cuja incipiência de informações sobre as condições de obtenção, manipulação e experimentação comprometem a reprodutibilidade e desenvolvimento da área. Discutese a inclusão dos invertebrados nos debates éticos cuja reivindicação de normatizações e proteção, demanda a instrumentalização do pesquisador em busca pela excelência técnica e ética no planejamento, execução e divulgação de sua pesquisa a fim de fortalecer o contrato social e cientifico gerador de benéficos para ciência e para qualidade de vida do animal.

Palavras-chave: bioética, ética animal, especismo, invertebrados, integridade na pesquisa

\section{Resumen}

Nuestro objetivo fue evaluar la promoción del bienestar de invertebrados utilizados en la investigación a través de su representación en la comunidad científica, la difusión de las investigaciones y la inclusión en los debates éticos. El análisis arrojó como resultado el predominio de los enfoques biológicos, utilitaristas en animales de interés médico y económico, cuya insipiencia de informaciones sobre las condiciones de obtención, manipulación y experimentación comprometen la reproducibilidad y desarrollo del área. Se discute la inclusión de los invertebrados en los debates éticos cuya reivindicación de normas y protección, demanda la instrumentalización del investigador en busca de la excelencia técnica y ética en la planificación, ejecución y difusión de sus investigaciones, con el fin de fortalecer el contrato social y científico generador de beneficios para la ciencia y para la calidad de vida del animal.

Palabras clave: bioética, ética animal, especismo, invertebrados, integridad en la investigación.

We aimed to evaluate the promotion of the welfare of invertebrates used in research through their representation in the scientific community, the dissemination of research and inclusion in ethical debates. The analysis resulted in the predominance of biological, utilitarian approaches in animals of medical and economic interest, whose incipience of information on the conditions of collecting, manipulation, and experimentation compromise the reproducibility and development of the area. It is discussed the inclusion of the invertebrates in the ethics debates, whose claim for standards and protection, demands the exploitation of the researcher in search of technical and ethical excellence in the planning, execution and dissemination of his research to strengthen the social and scientific contract generator of benefits to science and to the animal's quality of life.

Keywords: Bioethics, animal ethics, speciesism, invertebrates, integrity in research. 


\section{Introdução}

A utilização de animais como meio de conhecimento desenvolve-se há mais de 2 mil anos atrelada à discussão sobre sua legitimidade confrontando evidências biológicas convergentes e divergentes entre animais humanos e não-humanos (Fischer e Oliveira, 2012). A adesão aos testes em animais é embasada no antropocentrismo e na convicção mecanicista de que os animais não possuem consciência, enquanto o repúdio incompatibiliza-os com o direito animal, conclamando por técnicas substitutivas (Felipe, 2009; Fischer e Oliveira, 2012). Contudo, a legislação foi estruturada na proteção dos vertebrados, apoiada em evidências de que os invertebrados, embora possam possuir nocicepção, associando respostas involuntárias ao dano tecidual, nem todos são dotados de senciência, ou seja, processos mentais conscientes associativos de respostas emocionais negativas ao dano (Elwood 2011, Crook 2013). As exceções referem-se à Suécia, que inclui todos os invertebrados nas normativas legais e o Reino Unido e Canadá, que incluem os cefalópodes (Regis e Cornelli, 2012), corroborando a aderência de cientistas ao Manifesto de Cambridge atestando a existência de receptores para dor em invertebrados como moluscos e artrópodes e o questionamento da suficiência dessa evidência para suas inclusões na comunidade moral, provendo-os de proteção legal (Low, 2012).

No Brasil, embora a proteção jurídica dos animais configure desde o Código Civil de 1916, incrementado na Constituição Federal de 1988, se consolidou com a implementação das Leis de Crimes Ambientais (9.605/1998) e Arouca (11.794/2008) (Fischer e Oliveira, 2012, Lira et al., 2016) (Brasil, 1916, 1988, 1998), sendo que a última regulamen- ta os procedimentos experimentais com vertebrados submetendo as pesquisas e as aulas práticas às normatizações do Conselho Nacional de Experimentação Animal (CONCEA) por meio da Diretriz Brasileira para o Cuidado e a Utilização de Animais para fins Científicos e Didáticos (DBCA) e supervisão de uma Comissão de Ética no Uso de Animais (CEUA) (CONCEA, 2015).

A DBCA condiciona a pesquisa com vertebrados a uma justificativa válida, relevância científica, ausência de métodos alternativos e aplicação do princípio dos 3R's (CONCEA, 2015). O princípio dos 3R's (Replacement, Reduction e Refinement) (Russell e Burch, 1959) preconiza a redução ao máximo do número de animais, sem prejuízo ao experimento; o refinamento metodológico, tecnológico e estatístico visando o mínimo de sofrimento e dor, além de prover ao animal condições que elevem o grau de bem-estar-animal (BEA) antes, durante e após a intervenção; e a substituição dos animais por métodos alternativos tecnológicos ou por animais com menor grau de senciência. Nestes, inserem-se os invertebrados, sendo o uso legitimado pela destituição de senciência (Mather, 2011).

A base filosófica e ética com relação aos animais tem variado pouco, sendo contraposta em princípios contratualista, utilitarista e abolicionista (Mather, 2011). A primeira considera a aplicação do BEA vinculado a interesses próprios; a segunda atrela perdas/ganhos quanto à atribuição moral ao princípio da igual-consideraçãode-interesses em não sofrer dos animais (Singer, 2004); e a última, liderada pelo movimento pró-animal, defende o direito dos animais de não serem explorados como recursos para nenhuma necessidade huma- 
na, ampliando o princípio-da-igual-consideração-de-interesses em não sofrer, para interesse em viver, uma existência plena e natural, contudo ainda apoiada no senciocentrismo (Regan, 2004, Francione, 2013). As demandas da sociedade contemporânea não encontram respaldo integral nas abordagens tradicionais demandando o estabelecimento de novos paradigmas pautados em correntes éticas biocêntricas e ecocêntricas. Enquanto a primeira considera o valor intrínseco de cada animal, independente da sua complexidade física (Felipe, 2009), o ecocêntrismo visa a valoração do ecossistema como um todo, priorizando o equilíbrio do ambiente e valor intrínseco da natureza (Almeida, 2010).

A distinção entre invertebrados e vertebrados é artificial e meramente acadêmica, uma vez que os mesmos congregam cerca de $95 \%$ da fauna e de todos os filos do Reino Animalia, cuja diversidade e abundância é intrínseca à manutenção da vida cumprindo funções vitais na cadeia alimentar, como decompositores e polinizadores (New, 1995; Mather, 2011). O pouco conhecimento e disseminação de informações sobre a senciência dos invertebrados (Fischer, Librelato, Cordeiro, e Adami, 2016) somada à atribuição cultural de sua maleficência (New, 1995, Horvath et al., 2013) resulta na aderência por grande parte da sociedade, incluindo pesquisadores e acadêmicos, da não atribuição de status moral, considerando-os incogniscientes, inconscientes e não sencientes (Naconecy, 2007), automaticamente privando-os de cuidados.

A senciência cientificamente apoiada nas evidências de estrutura do sistema nervoso, fisiologia, comportamento, evolução, cognição e repertório comportamental, têm sido testadas e paulatinamente identificadas em invertebrados (Crook e Walters, 2011, Fiorito et al., 2014, Knutsson, 2016), contudo apoiadas na crença que quanto mais complexo é o sistema nervoso mais impacto terá um BEA empobrecido (Broom, 2013). No entanto, o benefício-da-dúvida tem sido proposto como princípio ético aliado ao princípio da precaução, uma vez que até o presente momento não há conhecimento científico suficiente para refutar sua senciência, logo a dúvida deve garantir que sejam tratados de maneira a favorecer seu BEA (Elwood, 2011, Oliveira e Goldim, 2014). Neste contexto questões éticas na utilização de invertebrados têm sido apontadas e refletidas (Nash, 2004; Mather e Anderson, 2007; Carruthers, 2007; Clark, 2015), clamando pelo aprofundamento dos conhecimentos sobre a senciência (Levine, 1974; Harvey-Clark, 2011), para que esses animais sejam incluídos na esfera de proteção legal (Dutra, Oliveira, 2010; Oliveira e Goldim, 2014). A educação é indicada como uma chave para a mudança na concepção, conscientizando sobre a importância ecológica dos invertebrados (Nash, 2004; Tlusty et al., 2013). Oliveira e Goldim (2014) alertaram para a necessidade de mudanças na conduta e responsabilidade na utilização dos invertebrados para fins científicos, ressaltando a importância de utilizar mecanismos para melhorar as condições de sua manutenção (Levine, 1974; Santos-Silva et al., 2015), bem como a utilização de analgesia e anestesia durante procedimentos e eutanásia condizentes (Crook e Walters, 2011; Lewbart e Mosley, 2012).

Diante da consolidação das normatizações das pesquisas com vertebrados e na expectativa que o meio científico tem compreendido os motivos que conclamam 
mudanças de conduta ética em uma pesquisa íntegra com animais, ultrapassando a mera determinação legal e burocrática, a pergunta norteadora do presente estudo é se esses novos paradigmas têm sido incorporados pelo meio acadêmico para invertebrados mesmo sem a obrigação legal. As hipóteses testadas foram: a) a inserção científica e a responsabilidade social da pesquisa com invertebrados justifica a cobrança por uma pesquisa técnica e eticamente íntegra; b) a concepção da ética animal apenas sob o viés burocrático pode comprometer a integridade na pesquisa ao negligenciar as demandas de BEA dos invertebrados; c) a concepção de cuidado com o modelo animal é incompatível com o especismo; d) A Bioética constitui-se de ferramenta na instrumentalização do pesquisador quanto a decisões consistentes e conscientes de porquê, quando e como utilizar animais, além de subsidiar debates em outros segmentos sociais. Desta forma, objetivou-se: a) caracterizar a representação dos invertebrados no meio científico; b) verificar se as condutas demandadas para uma pesquisa ética já têm sido adotadas; c) examinar os argumentos, valores e princípios éticos defendidos pelos percursores da reflexão sobre a inclusão dos invertebrados nos debates éticos; d) promover a reflexão sobre a importância dos invertebrados e a sua inclusão nos debates bioéticos, com intuito de contribuir para mudanças de paradigmas nas condutas e a normatização das pesquisas assim como da responsabilidade social e ética das mesmas. Esse estudo se justifica diante da necessidade de instrumentalizar os pós-graduandos que utilizam animais em suas pesquisas, que sua responsabilidade social e científica deve ultrapassar as determinações legais e prezar pela integridade técnica e ética de seus resultados.

\section{Material e métodos}

A presente pesquisa se constitui numa análise quali e quantitativa com caráter exploratório e descritivo.

\section{Abordagem científica dos invertebrados}

A categorização das pesquisas com invertebrados foi realizada através da quantificação temporal de textos científicos recuperados do portal da CAPES utilizando como descritores o nome em latim de filos representativos cientificamente contendo mais de 2000 espécies descritas (Porifera, Cnidaria, Platyhelminthes, Nematoda, Rotifera, Annelida, Mollusca, Echinodermata, Bryozoa e Arhtropoda, subdividido, em Insecta, Myriapoda, Arachnida e Crustacea) condicionados aos termos: conservation, drugs, food, tests, survey, toxicity, biology, behavior e control. A amostragem foi realizada no dia $5 / 4 / 2016$, contemplando artigos indexados até 31/12/2015. O viés decorrente da réplica de registros foi minimizado buscando a homogeneização dos resultados utilizando os mesmos filtros para todos os termos amostrados em um mesmo período.

\section{Divulgação de pesquisa com invertebrados}

A avaliação da conduta de cientistas direcionada aos invertebrados se deu por meio da análise exploratória das descrições dos métodos veiculados em publicações nacionais e internacionais, distribuídas equitativamente nos estratos A1/A2/B1, na área interdisciplinar da avaliação/2012 (Plataforma Sucupira, 2017), na expectativa que periódicos de classificação mais alta exija maior rigor nas pesquisas veiculadas. Foram considerados no máximo 15 artigos de cada revista para cada categoria, acessando do mais recente 
para o mais antigo, até o ano de 2009. O material para análise foi recuperado dos sites de revistas disponibilizados gratuitamente, sendo avaliados 50 artigos de cada tema: biologia, comportamento, controle, ecologia e experimentação, cuja categorização por meio da técnica de análise de conteúdo de Bardin (2011), resultou nas categorias: a) Tipo de estudo e autorizações (coleta e CEUA); b) Obtenção do animal: coleta, fixação, captura, anestesia e transporte; c) Experimento: manutenção (laboratório, natureza), descrição; d) Macro e microambiente: temperatura, umidade, fotoperíodo, tamanho do recipiente, substrato, alimentação, limpeza; e) Finalização e destinação. Estas categorias foram eleitas por serem os critérios exigidos para a realização de pesquisas com vertebrados cujo BEA valida a integridade da pesquisa (CONCEA, 2015).

\section{Inserção dos invertebrados nos debates éticos}

Os artigos analisados foram recuperados do portal da CAPES utilizando o descritor invertebrates condicionados a ethics, considerando a indexação até 31/12/2015, resultando em 89 artigos, destes 38 se referiam ao CEUA, 26 não atendiam ao tema, 15 eram duplicados, restando dez textos, com os quais foram somados outros quatro obtidos de referências dos artigos analisados. O conteúdo foi submetido à análise exploratória quanto: a) objetivo; b) problemas identificados; c) correntes éticas balizadoras; d) fundamentos éticos; e) propostas de solução, sequencialmente organizado e definido o centro da investigação; a descrição analítica, contemplando a identificação de pontos convergentes e divergentes; e a interpretação com análise, reflexão e intuição baseada no estabelecimento de relações com a realidade e conexões de ideias.

\section{Análise de dados}

Para a análise dos dados categóricos de frequência da área de conhecimento dos artigos científicos de cada filo, foi considerado como hipótese nula a homogeneidade da amostra, para tal o valor absoluto das publicações de cada área foi comparado em um mesmo filo utilizando o teste não-paramétrico qui-quadrado, considerando o nível de significância de 95\%.

\section{Resultados}

\section{Abordagem científica dos invertebrados}

O registro de publicações resultou em 70.770 textos científicos com predominância de Crustacea e de pesquisas sobre biologia (figura 1, página 24).

A homogeneidade da amostra foi testada para cada filo por meio do teste do qui-quadrado sendo os valores significativamente maiores $(\mathrm{P}<0,05)$ acompanhados de asterisco $(*)$.

\section{Divulgação de pesquisa com invertebrados}

As informações disponibilizadas sobre as condições de BEA em artigos científicos, apresentaram baixa referência à licença de coleta e CEUA. As informações sobre obtenção e manutenção dos animais não apresentaram padrão e foram em sua maioria incipientemente descritas (figura 2, página 24).

A homogeneidade de cada categoria analisada foi acessada pelo teste do qui-quadrado, sendo destacados os valores significativamente expressivos $\left({ }^{*}\right)$ e inexpressivos ( $\left(^{-}\right)$ $(P<0,05)$. Seta para baixo representa amostras em que todos foram significativamente inexpressivos, e para cima, expressivos. 
Figura 1. Frequência relativa dos registros de publicações científicas com invertebrados

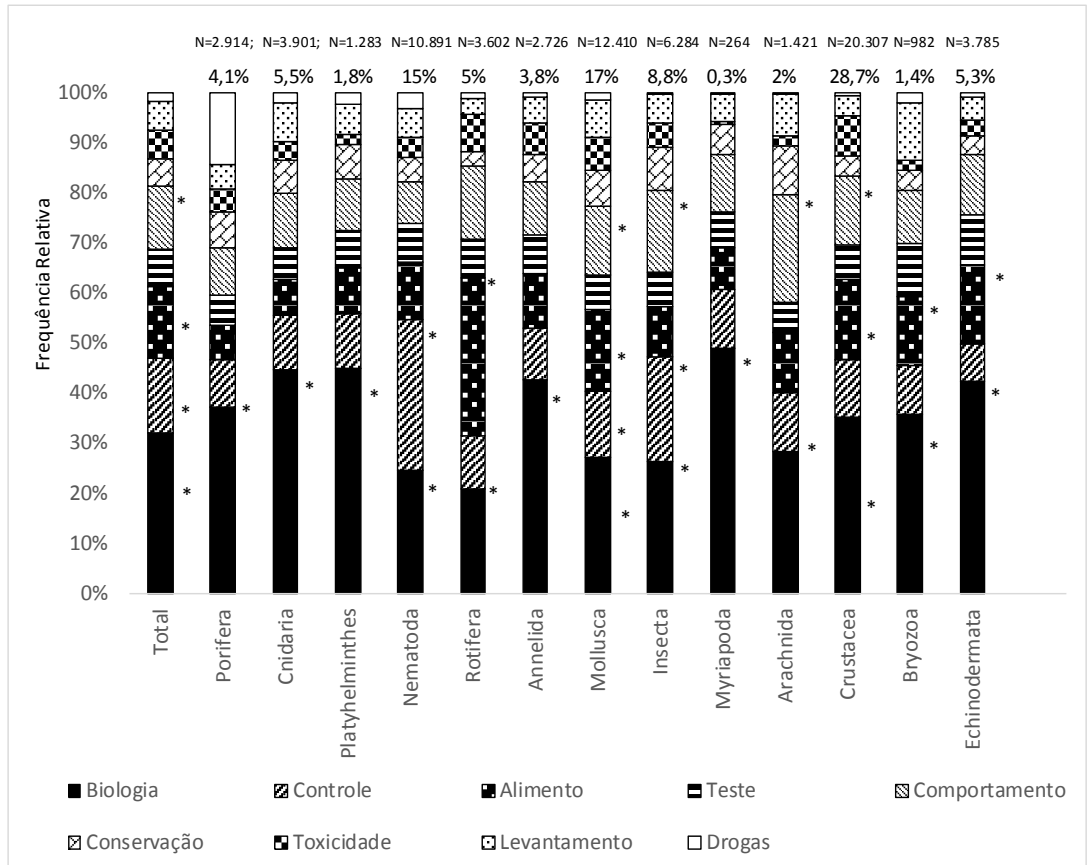

Figura 2. Número de artigos contemplante dos critérios de BEA de invertebrados

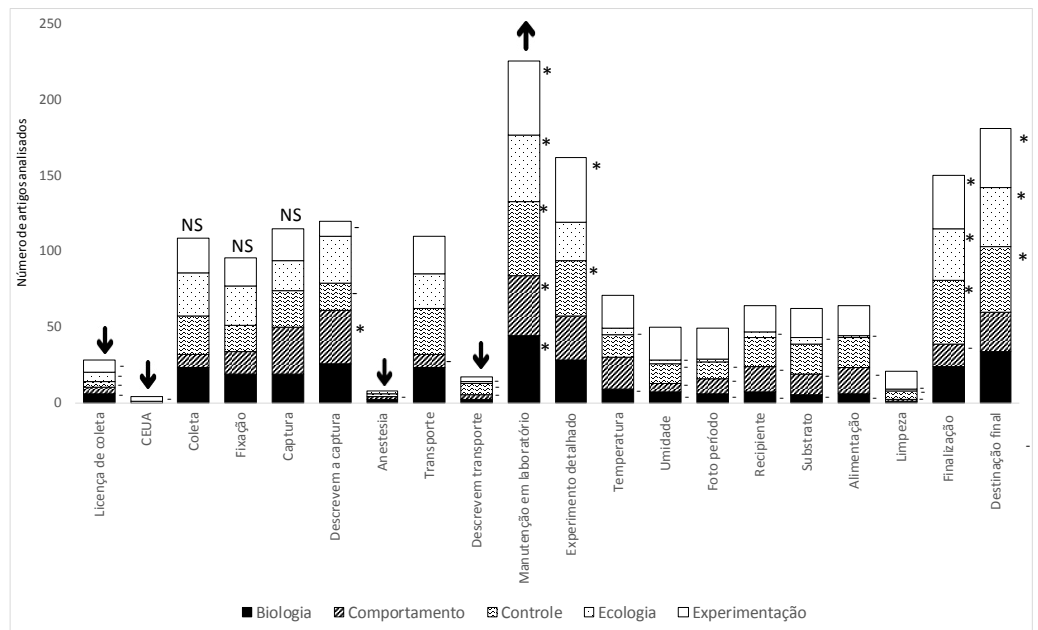




\section{Inserção dos invertebrados nos debates éticos}

A maioria dos textos recuperados com abordagem ética dos invertebrados eram posteriores ao ano 2000, sendo apenas três deles brasileiros. A descrição analítica revelou que a maioria detém mais de um obje- tivo, sendo a falta de empatia um dos principais problemas apontados, predominando à corrente ética bem-estarista e o princípio-da-igual-consideração-de-interesses, seguido pelo cuidado. As propostas englobaram mudanças de postura ética com relação aos invertebrados e sua inclusão na legislação de proteção animal (figura 3).

Figura 3. Descrição analítica dos artigos sobre ética em invertebrados

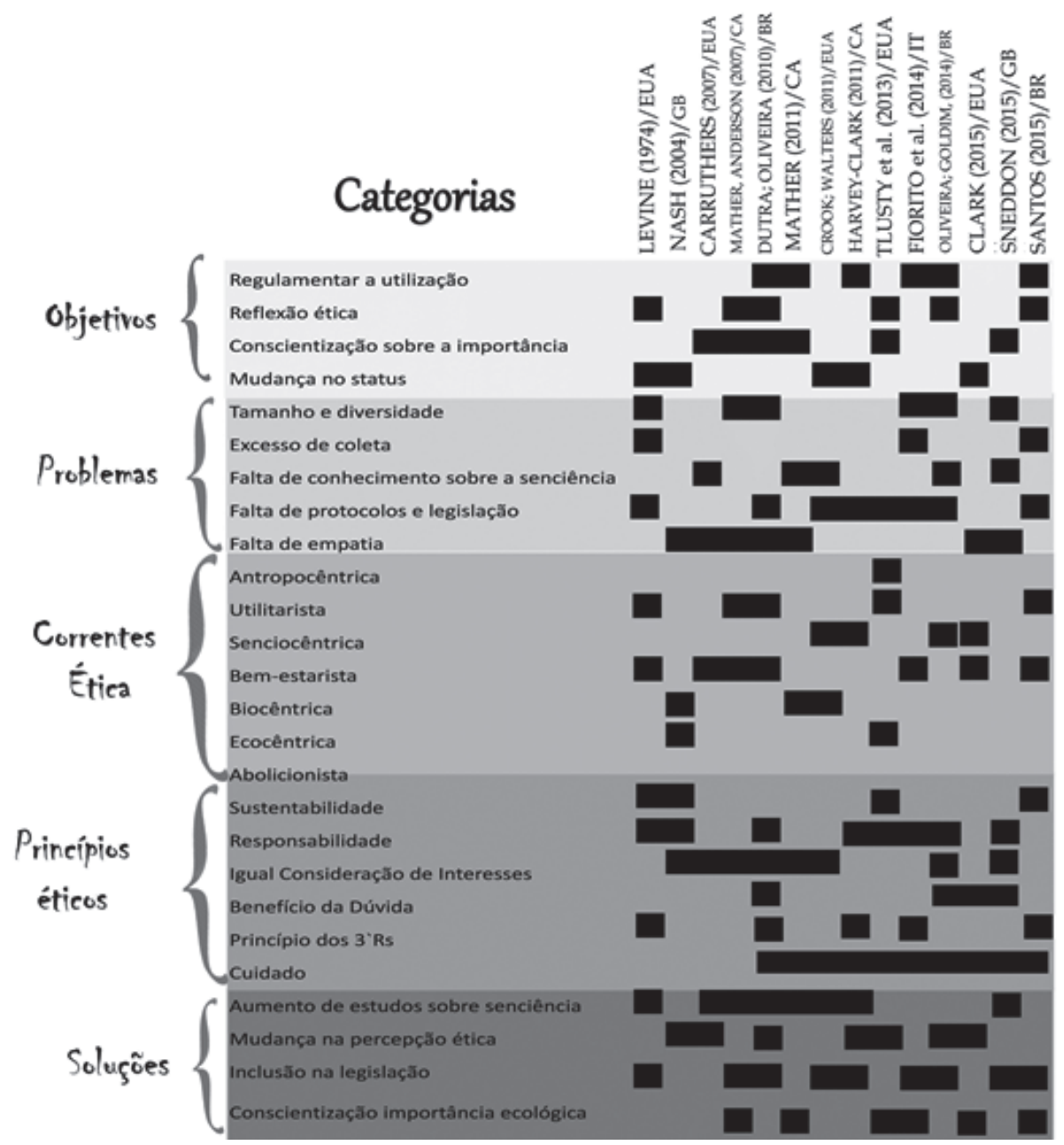

${ }^{*} \mathrm{O}$ preenchimento nos quadrados indica presença dos parâmetros nos textos. 


\section{Discussão}

Os resultados do presente estudo possibilitam o balizamento dos debates sobre a consolidação dos invertebrados nas discussões éticas. Por meio de análises quali e quantitativas se atestou que a relevante assimilação dos invertebrados pelo meio acadêmico não é simétrica à promoção de condutas éticas na realização da pesquisa e veiculação dos resultados. Fato este que pode atrasar ou até mesmo inviabilizar a aplicação de normativas éticas e legais nas pesquisas científicas com invertebrados.

A análise da produção científica evidenciou que a inserção das pesquisas com invertebrados reflete a diversidade de espécies e inter-relações com a sociedade, principalmente daquelas que provêm benefícios e malefícios diretos e indiretos (New, 1995, Mather, 2011), destacando-se estudos com crustáceos, moluscos e nematódeos. O mérito médico, econômico, farmacêutico ou ecológico de algumas espécies requer estudos básicos de biologia, tal como atestado na pesquisa e corroborado New (1995) que muito do conhecimento disponível advém da manutenção de invertebrados em laboratórios para experimentos, aulas, suprimento alimentar ou desenvolvimento de tecnologia. Justamente por se constituírem de estudos básicos, é necessário que se preze pela integridade, veracidade, reprodutibilidade e potencial de transpor da teoria para aplicação.

O direcionamento das pesquisas para invertebrados de interesse médico e econômico, legitima uma ciência fundamentada em princípios utilitaristas. Embora seja idôneo priorizar os estudos com animais que demandam intervenção diante dos impactos negativos na sociedade, New (1995) atentou para a necessidade de abordagens de conservação. Sendo esta tanto ao intuito de proteção de uma fauna pobremente conhecida, munida de poucos especialistas, ineficiente metodologia, inábil inserção em processos de comunicação e educação, bem como na utilização da estrutura de populações e comunidades como indicadores da saúde ambiental. New (1995) assinalou que a cultural demonização dos invertebrados tem configurado como um obstáculo para programas de conservação, mesmo diante do número mínimo de espécies com potencial de danos e inerente importância na manutenção dos ecossistemas. Contudo, tal como atestado no presente estudo, a representatividade de inventários ainda é insipiente. Considerando que apenas cerca de $10 \%$ das espécies do planeta foram descritas, New (1995) indicou a necessidade de aproximadamente 1000 anos para descrever apenas insetos cujo número de espécies desconhecidas provavelmente ultrapasse os 10 milhões. Segundo o autor, se faz necessário um esforço internacional na determinação de estratégias e desenvolvimento de técnicas de coleta e análises dos dados.

A análise dos procedimentos metodológicos apontou a deficiência de informações, o que inviabiliza a comparação e consequente avanço científico. Segundo Cooper (2011), diante da importância dos invertebrados e consequente despertar de interesse da ciência, o cuidado direcionado para aqueles indivíduos mantidos cativos deve ser tão alto quanto os destinados aos vertebrados, sendo o cuidado diretamente refletido na qualidade e integridade da pesquisa.

A pouca referência às CEUA está atrelada ao uso de invertebrados não ser regulamentado na maioria dos países, incluindo o Brasil (CONCEA, 2015). Consequentemente, 79\% das comissões participantes do Workshop que discutiu os sucessos e vicissitudes das CEUAs (Fischer et al., 2014) afirmou não 
avaliar pesquisas com invertebrados, mesmo diante da solicitação de pesquisadores subjugados a exigências editorais estrangeiras e de órgãos de fomento específicos. Por outro lado, CEUAs como da Pontifícia Universidade Católica do Paraná (PUCPR) possui protocolo específico e o número de invertebrados liberados já totalizam 15\% (Fischer; Librelato, 2012), englobando ostras, caranguejos, moluscos, mexilhões, anêmonas, minhocas, moscas, larvas de insetos, lagartas, baratas e aranhas em protocolos de pesquisa e aulas práticas (Fischer et al., 2014). O principal argumento contrário à avaliação de um projeto com invertebrados é a incipiência de parâmetros norteadores que inviabilizam uma avaliação eficaz. Contudo a DBCA, mesmo para vertebrados, alerta que não se deve considerar a ausência de parâmetros como justificativa, cujas deficiências devem ser superadas com o desenvolvimento de estudos pilotos e monitoramento do comportamento do animal. Oliveira e Goldim (2014) ressaltaram que os protocolos experimentais devem ser criteriosos, nos quais as ausências de parâmetros fisiológicos mais refinados possam ser supridas com estudos comportamentais (Elwood, 2011). Crook (2013) estimulou jovens pesquisadores e pós-doutorandos, que normalmente treinam integrantes da equipe e que rotineiramente estão em contato com as criações, a sistematizarem os procedimentos. Desta forma, avaliar o quanto a mudanças inseridas no processo de criação e manipulação resulta em animais mais saudáveis. O autor incentivou a análise do comportamento natural e a publicação de etogramas com padrões motores normais e aberrantes obtidos em diferentes condições, com e sem anestésicos, analgésicos e enriquecimento ambiental e identificação de sinais de desconforto e distresse. Consequentemente, cada laboratório que detém criações de invertebrados contribuiria para uma rede de conhecimento e melhoria de BEA em uma escala global. Knutsson (2016) foi além, apontando que a atenção dispendida para animais silvestres e invertebrados devem ultrapassar a legislação específica de captura e manejo e promover reflexões éticas sobre BEA de invertebrados, coletas didáticas redundantes, coleta por esgotamento, técnicas de manipulação e conservação, além do impacto do pesquisador no ambiente e no controle de pragas, clamando por métodos menos invasivos, principalmente preventivos.

A justificativa CEUA ter sido pouco abordada nos textos avaliados não está atrelado a pouca necessidade de autorizações de coleta/captura, uma vez que dispõe-se de severas leis ambientais nacionais e internacionais. Segundo New (1995), a legislação para invertebrados beneficia o grau de exploração visando a sustentabilidade da fauna como recurso e atua na regulamentação de transporte e introdução de espécies exploradas na alimentação ou no controle biológico. A aplicação dessas leis apresenta muitas limitações e vem sofrendo severas críticas, uma vez que o tamanho e distribuição dos animais inviabilizam a proteção individual, necessitando que o ecossistema seja protegido como um guarda-chuva para manutenção da integridade biológica. O direcionamento para uma proteção maior para espécies ameaçadas também esbarra no problema de como certificar dessa condição e a competência na identificação. Logo, o policiamento é difícil, principalmente em áreas remotas, cujas leis não têm sido hábeis na proteção dos ambientes como um todo. Por outro lado, os pesquisadores atribuem à burocracia para autorização um atraso nas pesquisas, provavelmente se abstendo voluntariamente de percorrer os processos burocráticos para legalização de 
suas pesquisas. No Brasil, as autorizações via SISBIO, Instituto Chico Mendes de Conservação da Biodiversidade (ICMBIO, 2017) monitoram além das espécies amostradas, a quantidade, local e metodologia. Embora não sejam cobrados BEA e não haja referência à adesão a princípios éticos, o formulário preenchido com cautela e responsabilidade pode se constituir de uma ferramenta para construção de uma pesquisa íntegra.

Apesar da maioria das metodologias analisadas envolverem a manutenção de invertebrados em laboratório, não houve associação com a descrição da obtenção dos mesmos. Um número significativamente baixo de autores se preocuparam em descrever o transporte e relatar o uso de anestésicos. O descaso na descrição de informações sobre as condições de obtenção e transporte omite dados importantes que podem influenciar o organismo e consequente resposta às intervenções experimentais e na interpretação dos resultados. Negligenciar a influência das condições de captura e transporte, ou deixar de adotar medidas para minimizar o impacto da mudança de ambiente e estresse, além de ser um descuido com o animal, podem comprometer a qualidade dos resultados da pesquisa, conforme tem sido atestado em vertebrados (Crissimuma e Almeida, 2006, CONCEA, 2015), e sugerido por Fischer, Aguero, Rodrigues, Silva, Moser, (2016) como uma orientação para normatização da conduta ética em consonância com a responsabilidade ética e social da pesquisa. Documentos oficiais como normas técnicas e operacionais associadas com vigilância, prevenção e controle de zoonoses já alertam para condutas na coleta e transporte dos animais vivos (Brasil, 2016).

Mesmo diante do aumento do uso de invertebrados nas pesquisas, a isenção do uso de anestésicos e analgésicos é uma prática comum (Cooper, 2011, Knutsson, 2016), apoiada na inexistência de senciência e de fármacos específicos. Porém pesquisadores como Dutra e Oliveira (2010), Lewbart e Mosley (2012) e Knutsson (2016) têm alertado para a importância da insensibilização da dor causada pela manipulação e experimentação como uma conduta ética e responsável. Cooper (2011) revisou os métodos disponíveis em literatura atestando que embora haja respostas específicas, condicionadas ao grau de susceptibilidade às intervenções dos fármacos, estado nutricional e de hidratação, a maioria dos métodos químicos de imobilização são livres de riscos. Segundo os manuscritos analisados as referências à finalização do animal e destino pós-pesquisa já passaram a configurar em estudos de controle, ecologia e experimentais, provavelmente refletindo a incorporação de uma conduta internalizada para vertebrados. Cooper (2011) e Lewbart e Mosley (2012) ressaltaram que os animais devem ser monitorados antes, durante e após a administração dos fármacos, considerando que os parâmetros de BEA e confirmação do relaxamento, sedação e eutanásia, que podem ser difíceis de serem atestados pelo fato da expressão desses processos serem, todavia, desconhecidos, diversificados ou dúbios, tais como animais que adotam a tanatose como estratégia de defesa. Logo a ausência de movimento necessariamente não representa ausência de dor e sofrimento. Para o autor o desenvolvimento de anestésicos e métodos de eutanásia para invertebrados devem se igualar aos de vertebrados, estruturados há mais de um século, ressaltando a importância destes na qualidade da pesquisa e no BEA. Para Lewbart e Mosley (2012) o aumento do uso econômico, ambiental, científico e doméstico justificam uma medicina de invertebrados. 
A mesma reflexão se aplica à incipiência de informações sobre as condições de manutenção. Supreendentemente foi insignificativamente o montante de artigos que veicularam informações sobre condições do macro e microambiente elementares tais como temperatura, umidade relativa do ar, fotoperíodo, recinto, substrato, alimentação e limpeza, apresentando uma aderência um pouco maior, mais ainda não significativa nos estudos experimentais. O fato de alguns pesquisadores considerarem os processos cognitivos dos invertebrados menos complexos, leva erroneamente à concepção que estes apresentem respostas automáticas e independentes de fatores externos, consequentemente desprivilegiam condições que favoreçam a elevação do seu BEA. A inexistência de protocolos e indicativos de dor e desconforto em invertebrados não deve ser tomado como justificativa para desconsiderar esse parâmetro na condução da pesquisa (Broom, 2013), mas sim, se constituir de uma área de desenvolvimento de pesquisa e tecnologia inovadoras e congregar informações como as relatadas por Horvath et al. (2013). Crissimuma e Almeida (2006) destacaram a incapacidade do animal em controlar suas reações metabólicas devido a fatores externos, como comprometedora dos resultados e automaticamente a integridade da pesquisa. Resultados diferentes podem ser obtidos, mesmo aplicando os mesmos parâmetros experimentais, quando realizados com animais em diferentes condições ambientais. Knutsson (2016) acrescentou a necessidade da regulação de BEA nas indústrias que praticam processos cruéis, tais como na produção da seda e carmim, e para os quais já existem alternativas sintéticas.

A análise qualitativa dos estudos pioneiros na promoção de discussões a respeito da inserção dos invertebrados nos debates éticos permitiu a identificação de duas linhas de reflexão: do ponto de vista ecológico e do filosófico, sendo possível a confluência de ambas por um mesmo autor.

$\mathrm{Na}$ abordagem ecológica destacaram-se a reivindicação de legislação e programas de educação ambiental objetivando conscientizar diferentes segmentos da sociedade quanto à importância de valores como respeito, precaução e sustentabilidade. Esta abordagem concebeu os invertebrados como recursos finitos e essenciais na manutenção dos ecossistemas para estas e futuras gerações (Horvath et al., 2013, Lira et al., 2016). Essa visão permeia áreas ambiental, econômica e jurídica balizadas pelo incentivo ao desenvolvimento de tecnologias que minimizem a superexploração (New, 1995) estimulando a busca por soluções que não prejudiquem o avanço técnico-científico, que ao mesmo tempo respeitem o ambiente visando equilíbrio entre a exploração de recursos naturais e a conservação da biodiversidade. O princípio da sustentabilidade trabalhado conjuntamente com o princípio de responsabilidade diante da vulnerabilidade da natureza (Jonas, 2006) abarca a tendência em assumir valores ecocêntricos, cuja atenção não é voltada para o indivíduo em si, mas para a teia de relações estabelecidas em um ecossistema. Neste contexto Fischer e Tamioso (2013) pontuaram a insistência da academia de não atribuir impacto às coleções científicas e didáticas de invertebrados apoiadas em projeções estatísticas que atestam pouco prejuízo nas populações apoiadas na abundância e alta taxa reprodutiva (Cooper, 2011, Lira et al., 2016), mas que segundo New (1995) podem potencializar as chances de extinção de determinadas espécies. 
A concepção dos invertebrados como modelo animal todavia é balizada por uma visão antropocêntrica/utilitarista e uma falsa sensação de conduta ética ao crerem estar praticando o princípio dos 3R's ao substituir vertebrados por invertebrados (Knutsson, 2016). Contudo, há uma mobilização para que o mesmo princípio seja aplicado para invertebrados visando minimizar a dor e sofrimento em intervenções com diferentes graus de invisibilidade (Crook, 2013). Desta forma, a justificativa e relevância do estudo devem ser fundamentadas em evidências e argumentos lícitos e idôneos; reduzir o número de animais sacrificados; incentivar o desenvolvimento de protocolos e tecnologia de biomarcadores para identificação de baixos graus de BEA e sua imediata mitigação; e buscar a substituição por métodos alternativos (Fiorito et al., 2014). Para Knutsson (2016) as evidências de que os invertebrados podem sentir dor devem ser suficientes para reduzir o sofrimento. Logo, quando possível não devem ser utilizados para atividades científicas e acadêmicas e nunca deveriam ser utilizados como alimento ou matéria prima, contudo até sua abolição, devem ser submetidos às normatizações no uso industrial e no controle. Crook (2013) e Cooper (2011) alertaram que caso o foco da justificativa esteja na correta identificação de dor, distresse e sofrimento, a promoção da BEA dos invertebrados permanecerá estagnada. Neste momento são necessárias mais informações sobre macro e microambiente, alimentação, interação social e manipulação associados com o habitat e hábitos específicos.

Nas reflexões pautadas no ponto de vista filosófico os autores abordaram a reflexão da necessidade de mudança do status de inferioridade atribuído aos invertebrados. Contudo, ainda se identifica discursos utilita- ristas, senciocêntricos e especistas que legitimam a utilização dos invertebrados mesmo atreladas a uma justificativa lícita e com isenção de dor e sofrimento (Felipe, 2009). Ressalta-se que nesse universo embora tenha predominado a demanda por incorporação de princípios éticos do cuidado, igual-consideraçãode-interesses e do benefício-da-dúvida, os textos que referiram-se ao princípio dos 3R's mostraram associação com a ética utilitarista/bem-estarista e a demanda por trabalhos técnicos que atestem a senciência e proteção legal dos mesmos. Francione (2013), contrário a qualquer utilização de animais como recursos para contemplar uma necessidade humana, não apresenta uma posição clara com relação aos invertebrados, evidenciando que o especismo está presente mesmo nos movimentos mais radicais, denominado por Naconecy (2007) como a Ética para vertebrados.

A similaridade da senciência de moluscos e humanos segundo Crook e Walters (2011) gera a obrigação moral de alocar cuidados a estes animais. Elwood (2011) indicou que 60\% de 13 grupos de invertebrados investigados responderam aos requisitos para senciência, contudo diante da ausência de dados conclusivos sugeriram cuidados mais humanitários consistentes com a ideia de que alguns invertebrados sentem dor. Para Naconecy (2007) semelhanças fisiológicas, comportamentais e genéticas são evidências suficientes para conceder o benefício-da-dúvida. Portanto, deve-se considerar que a preocupação e o cuidado em relação aos invertebrados são necessários devido ao valor intrínseco a cada ser vivo e seu direito a integridade física independente da confirmação de sua senciência (Carruthers, 2007, Mather, 2011). Broom (2013) ressaltou que a demanda por proteção está atrelada ao valor atribuído ao animal e esta pesa na decisão do 
porquê e quanto respeitar, considerar suas necessidades e usar meios para minimizar o sofrimento. Para o contexto científico e legal os parâmetros que comprovem a senciência são importantes, contudo Knutsson (2016) frisou que do ponto filosófico deve-se questionar o que será feito com essa informação. Fischer, Librelato, Cordeiro, e Adami. (2016) identificaram diferentes percepções da dor, emoções e afetividade em invertebrados cujo entendimento da natureza gradual da consciência fenomenal e estudos que subsidiam a existência de comportamento autônomos e complexos em muitas espécies balizam a necessidade de uma postura ética pautada em valores biocêntricos. Nesta visão, devese respeitar todo ser vivo que se move para se prover e almeja a sobrevivência, independentemente do tipo de senciência que detém. Os autores concluíram que embora a capacidade de sentir já tenha configurado como um parâmetro idôneo para segregar o ser humano da fauna, atualmente não se constitui de um argumento exclusivo e válido, justificando a aplicação integral do princípio da igualconsideração-de-interesses. Knutsson (2016) alertou que diante da expressividade numérica dos invertebrados, se de fato sentem dor, potencialmente considerada pela ciência, a quantidade de sofrimento imposta ao reino animal pelos humanos será catastrófica.

Identificando a necessidade do meio científico na utilização dos invertebrados e ao mesmo tempo a falta de informações quanto à realização e na veiculação dos experimentos, somando-se à preocupação emergente em discutir as questões éticas que permeiam as relações do ser humano com os invertebrados, percebe-se a necessidade de uma ferramenta mediadora e de promoção de diálogo. Argumentações éticas do contexto ecológico, utilitarista ou abolicionista (New,
1995, Fischer, Librelato, Cordeiro, e Adami, 2016, Crook, 2013, Mather, 2011, Lira et al., 2016) compactuam com a importância da comunicação e da educação, visando a aproximação de instâncias regulatórias, pesquisadores e sociedade por meio da promoção de cursos, treinamento, produção de guias na educação formal e não formal nos níveis de ensino básico, técnico ou superior. Atuando em instâncias legislativa, executiva e fiscalizadora públicas, privadas ou do terceiro setor. Com potencial de impacto no desenvolvimento cientifico, políticas públicas, convênios internacionais e esforços para aumentar o conhecimento sistemático, biológico e ecológico das espécies. Como coadjuvante desse processo se faz necessário conhecer a concepção e percepção de diferentes segmentos da sociedade (Mather, 2011, Fischer, Librelato, Cordeiro e Adami, 2016, Fischer e Tamioso, 2013 e 2016) e direcionar as intervenções (Horvath et al., 2013). Segundo Mather (2011), à medida que informações científicas são acessíveis para sociedade, o valor intrínseco do animal é aumentado e mais cuidado é direcionado, abolindo atitudes tradicionais cruéis como ferver caranguejos vivos para alimentação (Cooper, 2011). Crook (2013) sugeriu, ainda, aprimoramento na comunicação com ativistas, considerando o seu histórico com relação às mudanças de condutas com os vertebrados e potencial poder de presença pública. Neste sentido, a Bioética a partir de seu caráter interdisciplinar e de busca de soluções para questões ambientais globais (Fischer et al., 2017) poderia compor comitês multidisciplinares para avaliação e direcionamento de pesquisas e intervenções como proposta para outras questões como ecoturismo, animais sinantrópicos e crise hídrica (Fischer e Moinari, 2016). Por meio da promoção do diálogo entre o meio acadêmico, a sociedade, órgãos gestores 
e também dar voz aos invertebrados, visando encontrar as alternativas que atendam e representem, da melhor maneira possível, os interesses sociais, científicos e éticos.

\section{Considerações Finais}

Os resultados do presente estudo evidenciam que a importância científica dos invertebrados se mostrou assimétrica a preocupação com seu BEA. As lacunas identificadas na condução e veiculação de pesquisas, não condizem com o momento atual de avanço tecnológico, requerimento pela sociedade de esforços para solução de questões complexas e requisição de estudos inovadores e de excelência. A ausência de parâmetros na obtenção e manipulação de invertebrados pode atrasar essas expectativas, uma vez que muitos dados veiculados não podem ser validados, replicados e comparados devido à incipiência de informações. Além disso, podem acarretar em interpretações errôneas, incompletas que não geram ciência e demandam o uso de cada vez mais animais. Para os estudos com vertebrados tem se caminhado na busca de minimizar este viés, através de regulamentações que exigem que parâmetros mínimos sejam obedecidos para a realização de pesquisas, logo clamam-se por protocolos mínimos para invertebrados, mesmo diante da diversidade de hábitos e habitats e por recomendações especificas que assegurem a segurança humana, ambiental e BEA dos animais durante as intervenções e consequentemente, veiculação das reais condições em que as pesquisas ocorreram.

Concomitante ao desenvolvimento de pesquisas que atestam a senciência nos invertebrados, os pesquisadores devem aplicar os princípios éticos da igual-consideração-de-in- teresses e do benefício-da-dúvida fundamentados em concepções éticas biocêntricas e ecocêntricas cuja ausência de exigências legais deve ser irrelevante diante da inerente associação das atitudes de precaução e cuidado em relação aos invertebrados com a responsabilidade científica e social dos pesquisadores. Uma ciência de excelência se faz por meio de uma pesquisa íntegra, logo o pesquisador deve se ater ao rigor na elaboração, execução e divulgação da sua pesquisa. A escolha do modelo animal e a sua consequente obtenção, manipulação e experimentação deve ser realizada consistentemente e conscientemente de forma a prover condições para que atinja elevados graus de BEA e que todas as intervenções e condições experimentais sejam integralmente informadas, contribuindo igualmente para avanços na área de BEA de invertebrados. Consequentemente, a pesquisa de qualidade retroalimentará a relação de confiança entre Sociedade e Ciência.

O pesquisador, caso não seja instrumentalizado para assumir integralmente sua responsabilidade científica e social, poderá ser inserido em uma condição de vulnerabilidade diante de um sistema acadêmico, meritocrático e competitivo que o valoriza e o categoriza pela quantidade de publicações. A Bioética tem o papel de intermediar o diálogo entre os atores envolvidos em uma questão ética e intervir na busca de solução consensual e justa para todos. Assim, a partir do conhecimento dos argumentos de pesquisadores, editores, patrocinadores e sociedade balizados por valores comuns de prover uma ciência consistente, apoiada nos princípios éticos da responsabilidade, honestidade e imparcialidade, a Bioética deve prover instrumentos técnicos e legais para condução de uma pesquisa técnica e eticamente íntegra, por meio de processos educativos promo- 
vidos pelas instituições de ensino e CEUAs. $O$ pesquisador diante desses instrumentos formativos, consultivos, normativos e burocráticos deve se comprometer em se capacitar e cumprir com integridade as etapas de uma pesquisa científica e assumir sua reponsabilidade social quanto à qualidade e fidelidade dos dados, assim como a responsabilidade ética quanto a não geração de sofrimento e vulnerabilidades.

\section{Agradecimentos}

A estagiária graduanda do Curso de Ciências Biológicas Bianca Cardoso da Silveira Carvalho pela ajuda na coleta de dados.

\section{Referências}

Almeida, D. F. (2010). "Maus-tratos contra animais? Viro o bicho!": Antropocentrismo, Ecocentrismo e Educação AmFischer, M.L. e Molinari, R. (2016). Bioética ambiental: a retomada do cunho ecológico da bioética Em A. Sganzerla e F.R. Schramm, (Orgs.), Fundamentos da bioética (pp. 233-253). Curitiba: Editora CRV.

Bardin, L. (2011). Análise de conteúdo. (L. A. Reto e A. Pinheiro, Trad). São Paulo: Edições 70.

Brasil (1916). "Lei n. 3.071, de $1^{\circ}$ de janeiro de 1916". Código Civil dos Estados Unidos do Brasil. Recuperado de http://www.planalto.gov.br/ccivil_03/leis/L3071.htm.

Brasil, Constituição da República Federativa do Brasil de 1988. (1988). Constituição da República Federativa do Brasil de 1988. Brasília. Recuperado de http://www. planalto.gov.br/ccivil_03/Constituicao/ ConstituicaoCompilado.htm.
Brasil (1998). "Lei n. 9.605, de 12 de fevereiro de 1998". Condutas e atividades lesivas ao meio ambiente. Recuperado de http://www.planalto.gov.br/ccivil_03/ leis/L9605.htm

Brasil, Ministério da Saúdem Secretaria de Vigilância em Saúde y Departamento de Vigilância das Doenças Transmissíveis (2016). Manual de vigilância, prevenção e controle de zoonoses: normas técnicas e operacionais. Brasília: Ministério da Saúde.

Broom, D. M. (2013). The welfare of invertebrate animals such as insects, spiders, snails, and worms. Em: Kemp. T. A. van der e Lanchance, M. (Eds.), Animal Suffering: From Science to Law. Internaational Symposium (pp. 135-52). Paris: Éditions Yvon Blais.

Carruthers, P. (2007). Invertebrate minds: a challenge for ethical theory. The Journal of Ethics, 11(3), 275-297.

Clark, J. L. (2015). Uncharismatic invasives. Environmental Humanities, 6(1), 29-52.

Concea. (2015). Normativas do CONCEA para produção, manutenção ou utilização de amimais em atividades de ensino ou pesquisa científica. Lei, decreto, portarias, resoluções normativas e orientações técnicas. Recuperado de http://www.mctic.gov.br/ mctic/export/sites/institucional/institucional/arquivos/concea/240230.pdf

Cooper, J. E. (2011). Anesthesia, analgesia, and euthanasia of invertebrates. IlarJournal, 52(2), 196-204.

Crissiuma, A. L. e Almeida, E. C. P. (2006). Experimentação e bem estar animal-artigo de revisão. Saúde e Ambiente em Revista, 1(2), 1-10. 
Crook, R. A. (2013). The welfare of invertebrate animals in research: can science's next generation improve their lot. Journal of Postdoctoral Research, 1(2), 1-20.

Crook, R. J. e Walters, E. T. (2011). Nociceptive behavior and physiology of molluscs: animal welfare implications. Ilar Journal, 52(2), 185-195.

Dutra, B. K. e Oliveira, G. T. (2010). Ética com invertebrados Em A. Feijó, L. M. Gomez de Marcelo e Condessa Pitrez, P. M. (Orgs.), Animais na Pesquisa e no Ensino: aspectos éticos e técnicos. Porto Alegre: Edipucrs.

Elwood, R. W. (2011). Pain and suffering in invertebrates? Ilar Journal, 52(2), 175-184.

Felipe, S. T. (2009). Antropocentrismo, sencientismo e biocentrismo: perspectivas éticas abolicionistas, bem-estaristas e conservadoras e o estatuto de animais não-humanos. Páginas de Filosofia, 1(1), 2-30.

Fiorito, G., Affuso, A., Anderson, D. B., Basil, J. et al. (2014). Cephalopods in neuroscience: regulations, research and the 3Rs. Invertebrate Neuroscience, 14(1), 13-36.

Fischer, M.L., Aguero, W.P., Rodrigues, G.S., Silva, D.P.S. e Moser, A.M. (2016). Enriquecimento ambiental como princípio ético nas pesquisas com animais. Revista Bioetica, 24(3), 532-541.

Fischer, M.L., Cunha T. R., Renke V., Sganzerla, A. e Santos, J.Z. (2017). Da Ética Ambiental à Bioética Ambiental: antecedentes, trajetórias e perspectivas. História, Ciências e Saúde de Manguinhos, 24(2), 391-410.

Fischer, M.L., Librelato, R.F., Cordeiro, A.L. e Adami, E.R. (2016). A percepção da dor como parâmetro de status moral em animais não humanos. Conexão Ciências, 11, 31-41.

Fischer, M.L. e Oliveira, G.M. (2012). Ética no uso de animais: A experiência do Comitê de Ética no Uso de Animais da Pontifícia Universidade Católica do Paraná. Revista Estudos de Biologia, 34(83), 247-260.

Fischer, M. L., Prado, A.M.R, Oliveira, G.M.D., Tolazzi, A.L. et al. (2014). Concepção, implementação e consolidação do Comitê de Ética no uso de Animais da PUCPR. Estudos de Biologia, 36(1), 247-260.

Fischer, M. L. e Tamioso, P. R. (2013). Perception and position of animals used in education and experimentation by students and teachers of different academic fields. Estudos de Biologia: ambiente e diversidade, 35(84), 85-98.

Fischer, M. L. e Tamioso, P R. (2016). Bioética ambiental: concepção de estudantes universitários sobre o uso de animais para consumo, trabalho, entretenimento e companhia. Ciência e Educação, 22(1), 163-182.

Francione, G. (2013). Introdução aos direitos animais: seu filho ou o cachorro? (R. Rhoda Trad). Campinas: Editora Unicamp.

Harvey-Clark, C. (2011). IACUC challenges in invertebrate research. Ilar Journal, 52(2), 213-220.

Horvath, K., Angeletti, D., Nascetti, G. e Carere, C. (2013). Invertebrate welfare: an overlooked issue. Annali dell'Istituto superiore di sanità, 49(1), 9-17.

Instituto Chico Mendes de Conservação da Biodiversidade (iCMBio) (20149. Sistema de atendimento à distância de autorizações para coleta de material biológico (SIS- 
Bio). Recuperado de http://www.icmbio. gov.br/sisbio/

Jonas, H. (2006). O princípio responsabilidade: ensaio de uma ética para a civilização tecnológica. Rio de Janeiro: Contraponto.

Knutsson, S. (2016). Reducing suffering among invertebrates such as insects. Policy Paper by Sentience Politics, 1-18.

Levine, N. D. (1974). Use of marine invertebrates in biomedical research. Journal of invertebrate pathology, 23(1), 1-2.

Lewbart, G. A. e Mosley, C. (2012). Clinical anesthesia and analgesia in invertebrates. Journal of Exotic Pet Medicine, 21(1), 59-70.

Lira, M. G. S., Cantanhêde, L. G., Miranda, G. S. e Neta, R. N. F. C. (2016). Bioética E uso de animais invertebrados em pesquisa: Uma Abordagem Histórico-Legislativa. Investigação, 15(1).

Low, P. (2012). The Cambridge Declaration on Consciousness. Recuperado de http:// http://www.fcmconference.org/img/ CambridgeDeclarationOnConsciousness.pdf

Mather, J. A. (2011). Philosophical background of attitudes toward and treatment of invertebrates. Ilar Journal, 52, 205-212.

Mather, J. A. e Anderson, R. C. (2007). Ethics and invertebrates: a cephalopod perspective. Diseases of aquatic organisms, 75(2), 119-129.

Naconecy, C. M. (2007). Ética animal... Ou uma "ética para vertebrados"?: um animalista também pratica especismo? Revista Brasileira de Direito Animal, 2(3),
119-151.

Nash, S. (2004). Desperately seeking charisma: Improving the status of invertebrates. BioScience, 54(6), 487-494.

New, T. R. (1995). Introduction to invertebrate conservation biology. Oxford: Oxford University Press.

Oliveira, E. M. e Goldim, J. R. (2014). Legislação de proteção animal para fins científicos e a não inclusão dos invertebrados: análise bioética. Revista bioética. 22(1), 45-56.

Plataforma Sucupira (2014). Capes. Ministério da Educação. Recuperado de https://sucupira.capes.gov.br/sucupira/

Regan, T. (2004). Empty cages: Facing the challenge of animal rights. Maryland: Rowman e Littlefield.

Regis, A. H. e Cornelli, G. (2012). Experimentação animal: panorama histórico e perspectivas. Revista Bioética, 20(2), 232-243.

Russel, W. N. S. e Burch, I. (1959). The principles of humane experimental techniques. London: Universities Federation for Animal Welfare.

Dos Santos Silva, J., dos Santos Rocha, I. K. B., de Freitas, L. C., Pereira, N. J. et al. (2015). Princípios bioéticos aplicados aos estudos ecotoxicológicos aquáticos. Revista Bioética, 23(2), 409-418.

Singer, P. (2004). Libertação animal. São Paulo: Lugano.

Tlusty, M. F., Rhyne, A. L., Kaufman, L., Hutchins, M. et al. (2013). Opportunities for public aquariums to increase the sustainability of the aquatic animal trade. Zoo 